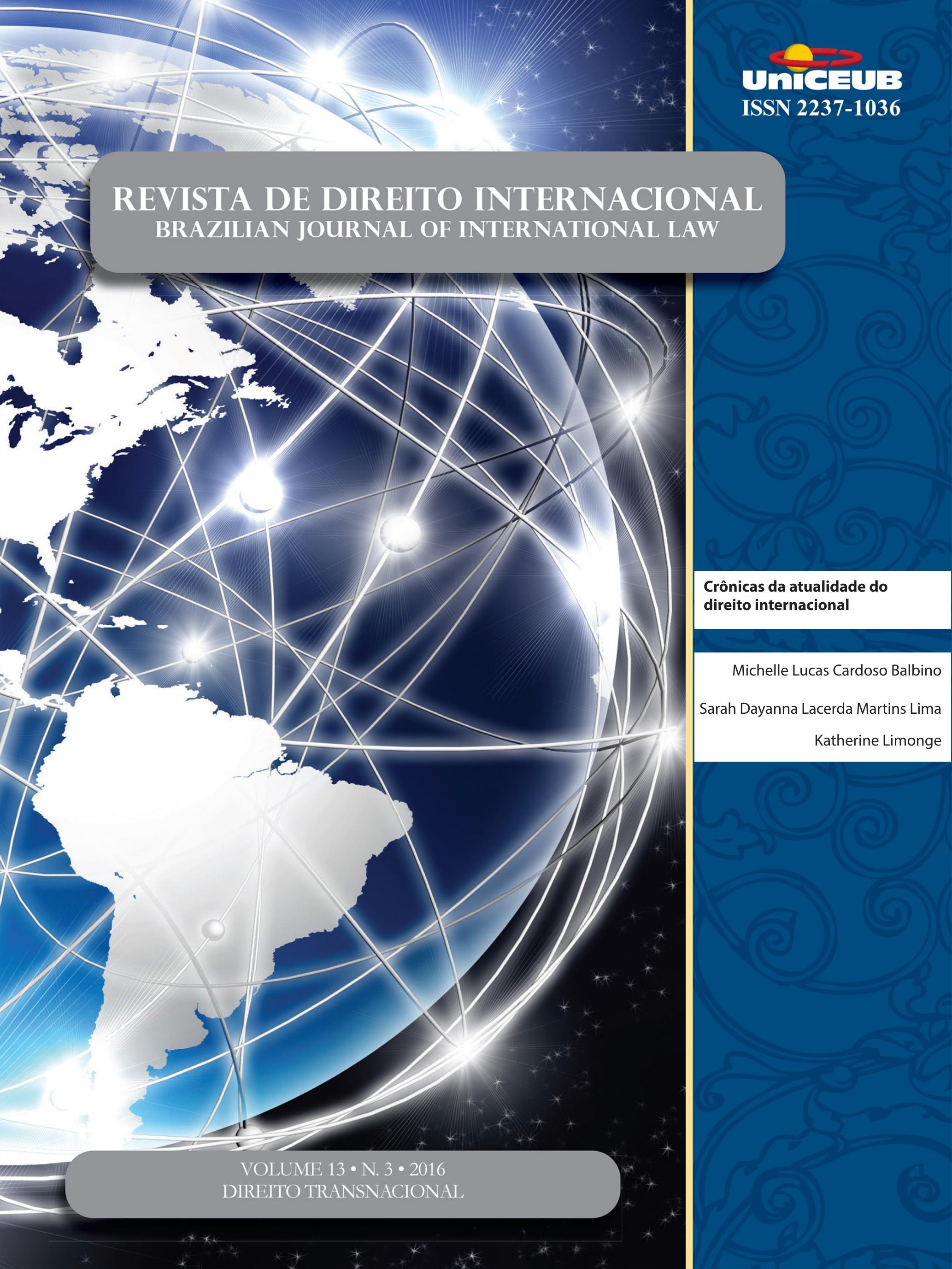


Crônicas da ATUALIdAde do direito internacional .................................................. 2

I. Dossiê Temático: Direito Transnacional .........................................................15

EDITORIAL: O Direito Transnacional - Circulação de normas e relações jurídicas transnacionais .......16 Priscila Pereira de Andrade

A emergênCia do direito transnacional ambiental .............................................18 Priscila Pereira de Andrade

Desafíos y RESPUESTAS TRANSNACIONALES FRENTE A LOS CRÍMENES AMBIENTALES ...............30 Rosmerlin Estupiñan-Silva

DiREITO TRANSNACIONAL E MUdANÇAS CLIMÁTICAS .50 Géraud de Lassus Saint-Geniès

Especies en movimiento: la Convención sobre el Comercio Internacional de Especies Amenazadas de Fauna y Flora Silvestres como espacio de “Encuentro” de discursos, ACTORES Y ESTRATEGIAS EN EL DERECHO AMBIENTAL TRASNACIONAL

María Valeria Berros e Dabel Leandro Franco

El carácter transnacional del Sistema comunitario de ECogestion « Eco-ManageMENT AND Audit SCHEME » (EMAS) DENTRo de LA UE y MÁs ALlÁ DE SUS Fronteras ......72 Adélie Pomade

O CONCEITO DE CONDUTA EMPRESARIAL RESPONSÁVEL À LUZ DOS ORDENAMENTOS JURÍDICOS BRASILEIRO, INTERNACIONAL E TRANSNACIONAL

Gabriel Webber Ziero

ARBITRAGEM NO DIREITO TRIBUTÁRIO INTERNACIONAL E NO DIREITO INTERNACIONAL DOS INVESTIMENTOS: UMA MANIFESTAÇÃO DO DIREITO TRANSNACIONAL

Vivian Daniele Rocha Gabriel 
O DIREITO TRIBUTÁRIO SOB UMA PERSPECTIVA TRANSNACIONAL

Franciele de Simas Estrela Borges

As Características do Direito Transnacional como Metodologia: Análise sob o enfoQue dos Aspectos Processuais da Arbitragem 126

Flávia Foz Mange

O DIREITO TRANSNACIONAL (“GLOBAL LAW") E A CRISE DE PARADIGMA DO ESTADO-CENTRISMO: É POSSÍVEL CONCEBER UMA ORDEM JURÍDICA TRANSNACIONAL? ...................................... 146

Luiza Nogueira Barbosa e Valesca Raizer Borges Moschen

TransPorte AÉREO E DIREITO TRANSNACIONAL: DA CONVERGÊNCIA À UNIFORMIDADE 160 Mickael R. Viglino

Outros Artigos. 175

O Fundo Monetário Internacional e a proteção dos direitos humanos: uma análise DO PROGRAMA DE CRESCIMENTO E REDUÇÃO DA POBREZA NO HAITI 177

Pablo Henrique Hubner de Lanna Costa e Carlos Alberto Simões de Tomaz

Um estranho no ninho? Padrões privados no Acordo de Barreiras Técnicas ao CoMÉRCIO DA OMC 192

Michelle Ratton Sanchez Badin e Marina Yoshimi Takitani

Os benefícios tributários do programa Inovar-Auto e os princípios da Nação Mais Favorecida e do Tratamento Nacional: uma análise dos argumentos dos Painéis atualmente em Curso contra o Brasil no Órgão de SoluÇão de Controvérsias da OMC . 211 Eric Moraes Castro e Silva

A ERA DA HUMANIDADE: REFLEXões PARA A HISTÓRIA DO DIREITO INTERNACIONAL 236 Henrique Weil Afonso

Precedentes vinculantes nos Estados Unidos da América e no direito brasileiro: Um ESTUDO COMPARADO 264

Patrícia Perrone Campos Mello 
IL DIRITTO AMBIENTALE SECONDO L'OTTICA DEL DIRITTO COSTITUZIONALE POSITIVO E LA RESPONSABILITÀ PER DANNI ALL'AMBIENTE NEL DIRITTO COMUNITARIO: LO STATO DELL'ARTE DEL DIRITTO AMBIENTALE COSTITUZIONALE E COMUNITARIO 287

Elcio Nacur Rezende

DA DESCONSIDERAÇÃo DA PERSONALIDADE JURÍDICA NAS RELAÇÕES CONSUMEIRISTAS BRASILEIRAS: ANÁLISE À LUZ DAS TEORIAS CLÁSSICAS

Daniel Amin Ferraz e Marcus Vinicius Silveira de Sá

ANALYSIS OF ADVANTAGES AND DISADVANTAGES OF FORUMS PRESCRIBED UNDER THE UNCLOS AND STATE PRACTICE: THE WAY AHEAD FOR INDIA ......................................................319

Vinai Kumar Singh

Do governo POR LEIS À governanÇA POR NúMERos: breve anÁlise do Trade in SERVICE AgreEMENT (TISA) ...............................................................................338 Jânia Maria Lopes Saldanha, Rafaela da Cruz Mello e Têmis Limberger

As DIRETIVAS EUROPEIAS COMO NORMA REGULADORA DO DIREITO ADMINISTRATIVO GLOBAL ..356 Alice Rocha da Silva e Ruth Maria Pereira dos Santos

O desenVolvimento da POlítica AGRícola COMUM dA UNião EUROPEIA 375 Tatiana de A. F. R. Cardoso Squeff

A imunidade de Jurisdição das organizaÇões internacionais FaCE AO Direito de aCESSO À JUSTIÇA 391

Fernanda Araújo Kallás e Caetano

O DIREITO INTERNACIONAL ENTRE O DEVER ÉTICO E A AÇÃo POLÍ́TICA: OS FUNDAMENTOS DE UM DEVER DE COOPERAÇÃO INTERNACIONAL NA FILOSOFIA POLÍTICA DE IMMANUEL KANT .405 Ademar Junior Pozzatti

EXTENSÃo E FRAGMENTAÇÃo NO CONTEXTO DA JURISDIÇÃO PENAL INTERNACIONAL .423 Marcus Vinícius Xavier de Oliveira

A DEFINiÇÃo JURÍdiCA DA "COMUNIDADE" .444 Nitish Monebhurrun, Michelle Lucas Cardoso Balbino, Fernanda Castelo Branco Araujo, Othon Pantoja, Míara Bogo Bruno e Cândida Dettenborn Nóbrega 
Comparative Study on Chinese Local Legislation of Science and Technology ProGRESS

LI Xiaoming e LI Yihan

O CONTROLE PENAL DO TRÁFICO DE PESSOAS: CONSTRUÇÃO JURÍDICA, INTERAÇÕES ORGANIZACIONAIS E COOPERAÇÃO INTERNACIONAL

Bruno Amaral Machado e Priscilla Brito Silva Vieira

Desativismo judicial: a extradição Battisti no Supremo Tribunal Federal .505 Francisco Rezek e Israel Paulino

A decisão norte-americana do Caso Myriad: novos paradigmas para a Proteção patenTÁRIA DO CÓDIGO GENÉTICO HUMANO E BIOTECNOLOGIA 514 José Carlos Vaz e Dias e Clarisse De La Cerda 


\section{Crônicas da atualidade do direito internacional}

Michelle Lucas Cardoso Balbino*

Sarah Dayanna Lacerda Martins Lima**

Katherine Limonge $\mathrm{e}^{* * *}$

\section{Crônica 1: Diretiva eURopeia de PROteÇÃo dos SEgRedos de NEGÓCIOS CONTRA A AQUISIÇÃO, UTILIZAÇÃO E DIVULGAÇÃO ILEGAIS: INCOERÊNCIAS JURÍDICAS ENCONTRADAS}

\section{INTRODUÇÃO}

A globalização representa um dos fatores que mais diferenciam a sociedade na atualidade e transformam as interações entre os atores envolvidos, principalmente no campo econômico. A globalização econômica possibilitou uma expansão no alcance territorial dos negócios realizados, que agora são feitos de forma global. Ao lado de desenvolvimentos recentes como o aumento da externalização, a expansão das cadeias de abastecimento e o uso acrescido de tecnologias da informação/comunicação, a globalização contribui para uma intensificação do mercado internacional. Ressalta-se que mesmo as empresas nacionais de pequeno e médio porte possuem possibilidades desses desenvolvimentos recentes e ampliam sua capacidade de participar do mercado internacional. ${ }^{1}$

Essa grande expansão das áreas de comércio internacional repercute, diretamente, na necessidade de inovação das empresas e, por consequência, amplia a cada dia o Direito Internacional dos Investimentos ${ }^{2}$. Um dos focos desse ramo do direito internacional está diretamente atrelado à exposição das atividades empresariais inovadoras às práticas desonestas, como apropriação indevida de segredos de negócios (roubo, cópia não autorizada, espionagem econômica ou violação de requisitos de confidencialidade ${ }^{3}$ ).

Vale considerar que já existem institutos de direitos de propriedade intelectual ${ }^{4}$ que constituem um dos meios para a proteção dos resultados de inovação e a proteção do acesso e da exploração de conhecimentos valiosos para a entidade que não sejam do conhecimento geral. Contudo, todas as

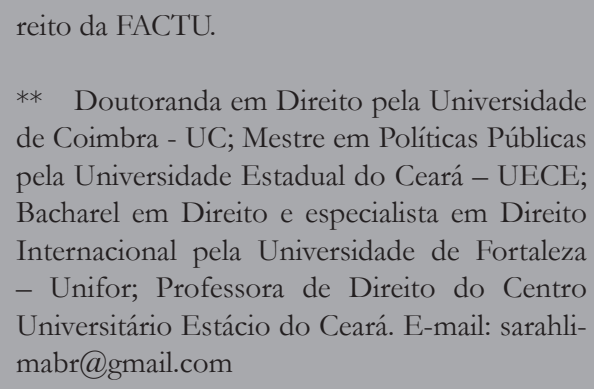

** Doutoranda em Direito pela Universidade de Coimbra - UC; Mestre em Políticas Públicas pela Universidade Estadual do Ceará - UECE; Bacharel em Direito e especialista em Direito Internacional pela Universidade de Fortaleza - Unifor; Professora de Direito do Centro Universitário Estácio do Ceará. E-mail: sarahlimabr@gmail.com

*** Mestranda em Direito pelo Centro universitário de Brasília
1 VARELLA, Marcelo Dias. Internacionalização do direito: direito internacional, globalização e complexidade. Brasília: UniCEUB, 2013.

2 Ramo específico do Direito Internacional, tendo como base, as definições de conteúdo político e econômico que envolve o poder dos Estados para regular os fluxos de capitais, o escopo de proteção que os Estados devem ou podem garantir aos investidores e as contradições inevitáveis entre os interesses gerais frequentemente afetados pelos investimentos estrangeiros e os direitos reconhecidos aos investidores (RIBEIRO, 2014).

3 A Diretiva de Proteção dos Segredos Comerciais da União Europeia define essas formas de apropriação indevida de segredos comerciais.

4 Como patentes, desenhos ou modelos ou direitos de autor. 
empresas, independentemente da sua dimensão ${ }^{5}$, valorizam, também, os segredos de negócios, tanto como as patentes e outras modalidades de direitos de propriedade intelectual. Esses segredos de negócios, considerados valiosos know-how ${ }^{6}$ e informações empresariais, são confidenciais e, para viabilizar os investimentos, é necessário que permaneçam confidenciais.

Quando ocorre a aquisição, utilização ou divulgação ilegais de um segredo de negócios, ocorre, também, um comprometimento na capacidade de o titular legítimo do segredo de negócios obter retornos de pioneiro decorrentes dos seus esforços relacionados com a inovação. Tal fator pode prejudicar o Direito Internacional dos Investimentos e com isso prejudicar a iniciativa inovadora das empresas. Afinal de contas, as empresas utilizam a confidencialidade como um instrumento de gestão da competitividade empresarial e da inovação na investigação.

Nesse quadro, observa-se que os segredos de negócios são uma das formas mais utilizadas pelas empresas para proteção da criação intelectual e do know-how inovador. Contudo, a proteção jurídica desse instituto era reduzida até a definição de uma nova norma instituída este ano pela União Europeia. Trata-se da Diretiva relativa à Proteção dos Segredos de Negócios, englobando know-how e informações comerciais confidenciais contra a sua aquisição, utilização e divulgação ilegais, aprovada em 14 de abril de 2016 pelo Parlamento Europeu. Porém, essa Diretiva representa um dos documentos mais criticados por jornalistas e organizações de proteção aos consumidores, tendo em vista as restrições impostas a concorrência comercial e a divulgação de informações (liberdade de comunicação social).

Cabe considerar que referida Diretiva normatizou a noção de informação confidencial, já prevista no art. 39 do Acordo sobre Aspectos dos Direitos de Propriedade Intelectual Relacionados ao Comércio (Agreement on Trade-Related Aspects of Intellectual Property Rights - TRIPS $)^{7}$. A ata final que incorpora os Resultados da

5 Para a Diretiva Europeia de Proteção dos Segredos Comerciais as pequenas e médias empresas (PME) valorizam ainda mais os segredos comerciais, pois possuem, ainda, mais dependentes deles. 6 Que representa um conjunto variado de informações que estão além dos conhecimentos tecnológicos (fórmulas secretas, informações, tecnologias, técnicas ou procedimentos) e abarcam dados comerciais tais como informações sobre os clientes e os fornecedores, planos de negócios e estudos e estratégias de mercado adquiridos pela empresa para ter vantagens competitivas.

7 Referido acordo foi assinado em 1994, durante o encerramento
Rodada Uruguai de Negociações Comerciais Multilaterais do GATT foi promulgada no Brasil pelo Decreto n. ${ }^{\circ} 1.355$, de 30 de dezembro de $1994^{8}$. O art. 39 do acordo TRIPS aponta para a necessidade de proteção de informação confidencial, assegurando a proteção efetiva contra a competição desleal, como disposto no art. 10bis da Convenção de Paris para a Proteção da Propriedade Industrial'. A Convenção de Paris proíbe, em particular, qualquer ato susceptível de criar confusão, por qualquer meio que seja, com o estabelecimento, produtos ou atividades industriais ou comerciais de um concorrente; alegações falsas, no exercício do comércio para desacreditar o estabelecimento, produtos ou atividades industriais ou comerciais de um concorrente; e, por fim, as indicações ou alegações, o uso, na vida comercial pode induzir o público em erro sobre a natureza, modo de fabricação, características, adequação para o emprego ou a quantidade dos produtos.

O próprio art. 39 do acordo TRIPS já apontava que tanto as pessoas físicas como jurídicas poderiam evitar que "informação legalmente sob seu controle seja divulgada, adquirida ou usada por terceiros, sem seu consentimento, de maneira contrária a práticas comerciais honestas" ${ }^{\prime 10}$.

Assim, o objetivo da Diretiva está no bom funcionamento do mercado interno (uniforme) em matéria de investigação e inovação relativa à proteção de know-how e de informações comerciais confidenciais (segredos de negócios) contra a sua aquisição, utilização e divulgação ilegais.

Muito se criticou em relação à adoção da nomenclatura "know-how" em virtude e não existir "qualquer

da Rodada Uruguai de Negociações Comerciais Multilaterais do GAT'T, momento em que se criou a Organização Mundial do Comércio (OMC).

8 BRASIL. Decreto n. 1.355, de 30 de dezembro de 1994. Promulga a ata final que incorpora os resultados da rodada Uruguai de negociações comerciais multilaterais do GATT. Disponível em: <http:// www.planalto.gov.br/ccivil_03/decreto/antigos/d1355.htm>. Acesso em: 14 jul. 2016.

9 Referida Convenção, assinada em 1967, define a necessidade de proteção eficaz contra a concorrência desleal é obrigação de todos os países signatários. Ademais, define que os atos de concorrência desleal são aqueles contrários às práticas honestas em matéria industrial ou comercial.

10 BRASIL. Decreto n. 1.355, de 30 de dezembro de 1994. Promulga a ata final que incorpora os resultados da rodada Uruguai de negociações comerciais multilaterais do GATT. Disponível em: <http:// www.planalto.gov.br/ccivil_03/decreto/antigos/d1355.htm>. Acesso em: 14 jul. 2016. 
significado autônomo e a sua utilização só contribuirá para acentuar a confusão terminológica em torno dos segredos de negócio". Neste aspecto, muitos apontavam, inclusive, que referido termo deveria ser ignorado $^{11}$. Contudo, deve-se ressaltar que referido termo foi descrito no texto final da Diretiva, apenas, nas considerações iniciais. Em relação ao texto normativo (artigos e parágrafos), tal nomenclatura não foi utilizada ${ }^{12}$.

Outra questão que merece consideração é a expressão segredo comercial existente na versão portuguesa da Diretiva. Alguns doutrinadores apontam que a expressão "segredo comercial" não deveria ser empregada, em face do direito brasileiro (considerando a noção jurídica de comércio no Brasil). Deveriam ter considerado a expressão "segredo de negócio", sendo apontado inclusive que deve estar sujeita a uma interpretação teleológica ${ }^{13}$ caso a transposição não seja corretamente feita ${ }^{14}$. Diante desses fatos, na presente crônica, será utilizado o termo "segredo de negócio" e não "segredo comercial".

Assim, observa-se que o objetivo apresentado pela Diretiva é a busca de facilidades na aplicação uniforme das medidas, dos procedimentos e das vias de reparação sobre o tema nos países que compõem a União Europeia (uniformização), a fim de evitar apropriação indevida de segredos de negócios. Ou seja, uma definição homogênea dos segredos de negócios, sem restringir o objeto a proteger contra apropriação indevida. Contudo, tal Diretiva vem sendo muito criticada e todas as críticas encontradas vão na contramão do objetivo geral da Diretiva, qual seja, a uniformização da atuação por todos os Estados-Membros.

Em relação aos principais pontos criticados ao longo das propostas e relatórios emitidos nos últimos anos, bem como aos textos finais aprovados, a liberdade de expressão e de informação (1) (que abrange a liberdade e o pluralismo dos meios de comunicação social) e a au-

11 SILVA, Nuno Sousa e. A proposta de directiva em matéria de segredos de negócio: uma primeira leitura. 2014. Disponível em: <http:// ssrn.com/abstract $=2459545$ or http://dx.doi.org/10.2139/ ssrn.2459545>. Acesso em: 01 jul. 2016.

12 Apesar do termo existente no texto do Relatório da Diretiva, este não constante no texto normativo final da Diretiva Europeia, estando mencionado apenas nas considerações iniciais para a execução e no título dado a mesma.

13 A interpretação teleológica, também, é conhecida por interpretação lógica.

14 SILVA, Nuno Sousa e. A proposta de directiva em matéria de segredos de negócio: uma primeira leitura. 2014. Disponível em: <http:// ssrn.com/abstract $=2459545$ or http://dx.doi.org/10.2139/ ssrn.2459545>. Acesso em: 01 jul. 2016. sência de ações uniformes ao longo da Diretiva (2) (deixando uma abertura no texto normativo para atuação dos Estados-Membros) representam pontos que devem ser discutidos.

\section{A LIBERDADE DE EXPRESSÃO/INFORMAÇÃO E A ABRANGÊNCIA DO PLURALISMO DOS MEIOS DE COMUNICAÇÃO SOCIAL: INCERTEZA JURÍDICA E O ÔNUS DE PROVA}

Um dos principais temas discutidos ao longo de toda a trajetória de elaboração dessa Diretiva foi a garantia do exercício, não limitado, do direito à liberdade de expressão e de informação, que abrange a liberdade e o pluralismo dos meios de comunicação social, conforme aponta o art. 11 da Carta dos Direitos Fundamentais da União Europeia (1). Uma possível limitação desse direito causou entre os jornalistas e associações de mídia da Europa grande preocupação, em particular no que diz respeito ao jornalismo de investigação e à proteção das fontes jornalísticas. Na discussão desse tema, é importante considerar dois pontos: a incerteza jurídica da aplicação final das garantias previstas pela Diretiva (1.1) e a necessidade de ônus de prova por parte do denunciante e jornalistas (1.2).

Vários jornalistas ${ }^{15}$ apontam que existe incerteza jurídica sobre a aplicabilidade dessa Diretiva em relação à proteção da liberdade de expressão (1.1). Tal incerteza poderia criar um efeito inibidor sobre os jornalistas, pois esse efeito estaria atrelado à necessidade de verificar/assegurar que as intenções do denunciante (fontes jornalísticas) realmente cumpriram os requisitos da Diretiva, antes de usar as informações (segredos de negócios) como sendo de interesse público ${ }^{16}$.

Após longas discussões e pareceres apresentados pelas partes interessadas, inclusive pela Comissão do Mercado Interno e da Proteção dos Consumidores, foi incluída, na versão final da Diretiva, a garantia exercício do direito à liberdade de expressão e de informação. A

15 Cabe destacar as reportagens feitas por: RSF (2016); DAMGE (2016); VAUDANO; DAMGE (2016) e RFJ (2016).

16 REPORTERS SANS FRONTIERES. Adoption de la directive sur le secret des affaires: le journalisme d'investigation doit être sauvegardé. 2016. Disponível em: < https://rsf.org/fr/actualites/adoption-dela-directive-sur-le-secret-des-affaires-le-journalisme-dinvestigationdoit-etre>. Acesso em: 14 jul. 2016. 
primeira versão da Diretiva não considerava nenhuma forma de proteção à liberdade de informação, sendo considerada uma afronta ao art. 11 da Carta dos Direitos Fundamentais da União Europeia.

Em que pese a inclusão no texto final aprovado pelo Parlamento Europeu, das garantias descritas acima, muitas preocupações ainda perduram no meio jornalístico, principalmente frente as incertezas jurídicas do texto apresentado, pois as exceções previstas na alínea "a" do art. 5 da Diretiva ${ }^{17}$, que considera o exercício da liberdade de expressão e de informação, não são claras e nem objetivas. Sua aplicação depende do modo de aplicação da Diretiva por cada Estado-Membro. Assim, não existe uma forma já padronizada de como aplicar o texto genérico descrito pela Diretiva ${ }^{18}$. Portanto, a Diretiva torna-se um texto genérico com necessidade de definição de ações de cada país para sua aplicação, o que coloca as associações de mídia em alerta em relação à transposição da Diretiva Europeia para as normas nacionais dos Estados-Membros, a fim de se certificar de que não está a ser aplicado de forma abusiva e sem respeito a liberdade de imprensa e da atividade dos denunciantes ${ }^{19}$. Esse problema direciona ao próximo item objeto de discussão dessa crônica, a não uniformização das medidas pela Diretiva (2.1).

Outro ponto que merece ser considerado é em relação à garantia de ausência de riscos a jornalistas e denunciantes quando da divulgação de informações sobre a empresa (1.2), pois, conforme apontado pelos jornalistas, os denunciantes são deixados, potencialmente, desprotegido, uma vez que existe a necessidade de provar que a divulgação de informações foi feita com a finalidade de proteger o interesse público geral (art. $5^{\circ}$,

17 "Os Estados-Membros asseguram que um pedido de aplicação das medidas, dos procedimentos e das vias de reparação previstos na presente diretiva seja indeferido caso a alegada aquisição, utilização ou divulgação do segredo comercial tenha sido realizada numa das seguintes circunstâncias: a) Para exercer o direito à liberdade de expressão e de informação, consagrado na Carta, incluindo o respeito pela liberdade e pelo pluralismo dos meios de comunicação social [...]". 18 REPORTERS SANS FRONTIERES. Adoption de la directive sur le secret des affaires: le journalisme d'investigation doit être sauvegardé. 2016. Disponível em: <https://rsf.org/fr/actualites/adoption-dela-directive-sur-le-secret-des-affaires-le-journalisme-dinvestigationdoit-etre>. Acesso em: 14 jul. 2016.

19 REPORTERS SANS FRONTIERES. Adoption of the trade secrets directive by the european parliament: investigative journalism must be guaranteed. 2016. Disponível em: <http://europeanjournalists. org/blog/2016/04/14/adoption-of-the-trade-secrets-directive-bythe-european-parliament-investigative-journalism-must-be-guaranteed/>. Acesso em: 14 jul. 2016. "b" da Diretiva) ${ }^{20}$.

Observa-se que a Diretiva deixa claro que o ônus da prova cabe a quem alega, ou seja, ao denunciante (inclusive ao jornalista) e não às empresas. Muitos alegam que referido ponto deixa o denunciante desprotegido, pois apenas cinco Estados-Membros da União Europeia dispõem de legislação abrangente sobre a proteção dos denunciantes (França, Reino Unido, Luxemburgo, Romênia e Eslovênia). Em contraposição, após discussão sobre esse ponto, a Comissão considerou que o disposto no art. $5^{\circ}$ da Diretiva é amplamente suficiente, pois não há necessidade de uma Diretiva para proteger os denunciantes ${ }^{21}$.

Acreditam, ainda, que a proteção dos denunciantes deveria ter sido objeto de Diretiva específica. Assim, a discussão maior gira em torno da proteção do denunciante, que, conforme definição da Diretiva, tem o ônus da prova e nenhuma garantia. Alguns desejava que a definição da proteção do denunciante deveria ter sido adotada ao mesmo tempo que a Diretiva relativa ao sigilo comercial, para garantir a manutenção do equilíbrio (empresa versus interesse público/denunciante) ${ }^{22}$.

Observa-se que tanto a incerteza jurídica como o ônus de prova representam pontos de inibição para que ocorram denúncias que visam proteger o interesse público geral nos casos de segredos de negócios. A Diretiva tentou regulamentar a questão a nível europeu, contudo, como não apontou ações de proteção ao denunciante (definindo reais limites), manteve a incerteza de atuação dos Estados-Membros, inviabilizando a real operacionalização da norma de forma uniforme.

O Parlamento perdeu uma ótima oportunidade para definir diretrizes e limites para atuação do denunciante em sede dos segredos de negócios. Tal fato deve-se a grande pressão realizada pelas empresas ${ }^{23}$. Assim, achou

20 REPORTERS SANS FRONTIERES. Adoption de la directive sur le secret des affaires: le journalisme d'investigation doit être sauvegardé. 2016. Disponível em: <https://rsf.org/fr/actualites/adoption-dela-directive-sur-le-secret-des-affaires-le-journalisme-dinvestigationdoit-etre>. Acesso em: 14 jul. 2016.

21 DAMGE, Mathilde. Dossier secret des affaires-adoption par le parlement européen dun texte protégeant le secret des affaires. 2016. Disponível em: <https://jscheffer81.wordpress.com/dossier-secret-des-affaires-adoption-par-le-parlement-europeen-dun-texte-protegeant-lesecret-des-affaires/>. Acesso em: 14 jul. 2016.

22 VAUDANO, Maxime; DAMGE, Mathilde. Ce qu'il faut savoir de la directive sur le secret des affaires. 2016. Disponível em: <http:// www.lemonde.fr/les-decodeurs/article/2016/04/19/ce-qu-il-fautsavoir-de-la-directive-sur-le-secret-des-affaires_4904548_4355770. html\#1kUhtsEAuVIx9uSZ.99>. Acesso em: 14 jul. 2016.

23 O que pode ser observado quando da análise do Parecer elabo- 
conveniente deixar tais fatos para outra Diretiva, mais específica, sobre o tema da proteção do denunciante.

\section{Cláusulas abertas e a manutenção dos PROBLEMAS JURÍDICOS: UMA UNIFORMIZAÇÃO NÃO TÃO UNIFORME}

Um grande problema encontrado na Diretiva de Proteção dos Segredos de Negócios contra a aquisição, utilização e divulgação ilegais é a existência de cláusulas abertas quando do seu enquadramento jurídico em cada Estado-Membro, ou seja, aberturas para que cada Estado-Membro possa definir a forma de aplicação internamente da Diretiva.

Ao longo da Diretiva, verificou-se a definição de texto genérico para a definição das garantias à liberdade de expressão e direitos dos denunciantes (2.1), bem como a ausência de menção das formas de utilização e divulgação legais dos segredos de negócios (2.2), além da autorização para que as autoridades judiciais ajam por sua própria iniciativa (2.3) e, por fim, que os Estados-Membros podem definir que os pedidos de indenização possam ser feitos em processos judiciais apartados (2.4). Observa-se que todos os pontos acima influenciam, diretamente, na não uniformização de certas medidas, procedimentos e vias de reparação sobre o tema nos países que compõem a União Europeia.

Como apontado no item anterior (1.1), a Diretiva Europeia possui texto genérico para a definição das garantias à liberdade de expressão e direitos dos denunciantes (2.1). Cada Estado-Membro pode definir como suas ações serão aplicadas. Nesse ponto, observa-se que a Diretiva possui objetivo geral de uniformizar os procedimentos realizados sobre os segredos de negócios. Com a definição de cláusula aberta, conforme dispõe a alínea "a" do art. 5 da Diretiva, torna-se inviável a padronização do exercício do direito à liberdade de expressão e de informação, consagrado na Carta dos Direitos Fundamentais da União Europeia, incluindo o respeito pela liberdade e pelo pluralismo dos meios de comunicação social. Ademais, não há como certificar que o exercício desses direitos está sendo preservado em cada Estado-Membro, quando se tem formas aber-

rado pela Comissão da Indústria, da Investigação e da Energia, que ditou muitas das alterações realizadas ao longo das discussões até a redação final do texto da Diretiva Europeia. tas de interpretação por cada ente da União Europeia.

Outra considerável análise pode ser feita em relação à menção das formas de aquisição, utilização e divulgação legais dos segredos de negócios (2.2), previstas no art. $3^{\circ}$ da Diretiva Europeia de Proteção dos Segredos de Negócios. Ao listar os meios passíveis de aquisição legal do segredo de negócios, o artigo $3^{\circ}$ não apresentou as modalidades de utilização e divulgação, deixando em aberto a interpretação dessas possibilidades. Ao contrário, o art. $4^{\circ}$ a Diretiva determinou tanto as formas de aquisição, com as formas de utilização e divulgação ilegais dos segredos de negócios.

Assim, observa-se que a aquisição possui rol taxativo de possibilidades legais e também rol taxativo de possibilidades ilegais. Já a utilização e divulgação, apenas, definiram o rol taxativo de ilegalidades, não restringindo as formas de utilização e divulgações legais. Veja quadro abaixo para melhor visualização do apontado acima:

Quadro 01 - Formas legais e ilegais de aquisição, utilização ou divulgação de segredos de negócios

\begin{tabular}{|c|c|c|}
\hline FORMA & LEGAL & ILEGAL \\
\hline AQUISIÇÃO & $\begin{array}{l}\text { Descoberta ou } \\
\text { criação independente; } \\
\text { Observação, estudo, } \\
\text { desmontagem ou } \\
\text { teste de um produto } \\
\text { ou objeto que tenha } \\
\text { sido disponibilizado } \\
\text { ao público ou que } \\
\text { esteja legalmente na } \\
\text { posse do adquirente } \\
\text { da informação, não } \\
\text { estando este sujeito } \\
\text { a qualquer dever } \\
\text { legalmente válido de } \\
\text { limitar a aquisição do } \\
\text { segredo comercial; } \\
\text { Exercício do direito } \\
\text { dos trabalhadores ou } \\
\text { dos representantes } \\
\text { dos trabalhadores a } \\
\text { informações e con- } \\
\text { sultas em conformi- } \\
\text { dade com o direito } \\
\text { da União ou com as } \\
\text { legislações e as práti- } \\
\text { cas nacionais; } \\
\text { Outras práticas que, } \\
\text { nas circunstâncias } \\
\text { específicas, estejam } \\
\text { em conformidade } \\
\text { com práticas co- } \\
\text { merciais honestas. } \\
\text { (art. } 3^{\circ} \text { ) }\end{array}$ & $\begin{array}{l}\text { Acesso, apropriação } \\
\text { ou cópia não au- } \\
\text { torizados de docu- } \\
\text { mentos, objetos, } \\
\text { materiais, substâncias } \\
\text { ou ficheiros eletrôni- } \\
\text { cos, legalmente sob } \\
\text { controlo do titular } \\
\text { do segredo comer- } \\
\text { cial, que contenham } \\
\text { o segredo comercial } \\
\text { ou a partir dos quais } \\
\text { seja possível deduzir } \\
\text { o segredo comercial; } \\
\text { Outras condutas que, } \\
\text { nas circunstâncias } \\
\text { específicas, sejam } \\
\text { consideradas con- } \\
\text { trárias às práticas } \\
\text { comerciais honestas. } \\
\text { (art. } 4^{\circ} \text {, item 2) }\end{array}$ \\
\hline
\end{tabular}




\begin{tabular}{|c|c|c|}
\hline FORMA & LEGAL & ILEGAL \\
\hline $\begin{array}{c}\text { UTILIZAÇÃO } \\
\text { OU } \\
\text { DIVULGAÇÃO }\end{array}$ & $\begin{array}{l}\text { Não definido na } \\
\text { norma }\end{array}$ & $\begin{array}{l}\text { Aquisição ilegal; } \\
\text { Viole acordo de } \\
\text { confidencialidade } \\
\text { ou qualquer outro } \\
\text { dever de segredo } \\
\text { comercial; } \\
\text { Viole dever contra- } \\
\text { tual ou qualquer ou- } \\
\text { tro dever de limitar a } \\
\text { utilização do segredo } \\
\text { comercial. (art. } 4^{\circ} \text {, } \\
\text { item 3) }\end{array}$ \\
\hline
\end{tabular}

Fonte: art. $3^{\circ}$ e $4^{\circ}$ da Diretiva Europeia

Verifica-se que, nesse ponto, houve uma abertura na possibilidade de regras por parte dos Estados-Membros em relação à internalização da norma no direito nacional, pois deixou à escolha de cada ente a aplicação das formas de utilização e divulgação legais dos segredos de negócios, pois não houve a definição dessas modalidades pela norma, sendo apontadas, apenas, as restrições (formas ilegais) de realização da utilização ou divulgação do segredo de negócios.

Tal fato causa insegurança jurídica, pois não precisou regras específicas para a utilização e divulgação, podendo cada Estado-Membro definir sua forma de atuação interna, conforme dispõe o ponto 2 do art. $3^{\circ}$ ao considerar que "A aquisição, utilização ou divulgação de um segredo de negócio é considerada legal na medida em que tal aquisição, utilização ou divulgação seja imposta ou permitida pelo direito da União ou pelo direito nacional".

Assim, tal fato deixa em aberto, mais uma vez, a atuação dos Estados-Membros em relação à interpretação aplicada em cada caso. Tal fato vai na contramão, mais uma vez, ao objetivo geral da Diretiva, qual seja a uniformização medidas, dos procedimentos e das vias de reparação sobre o tema nos países que compõem a União Europeia.

Em vários momentos, a Diretiva aponta que "Os Estados-Membros podem também permitir que as autoridades judiciais competentes ajam por sua própria iniciativa" (2.2). Tal ponto retira mais uma vez a possibilidade de uniformização da atuação no presente tema, uma vez que representa a possibilidade de "ativismo judicial" do magistrado em relação à preservação da confidencialidade dos segredos de negócios durante os processos judiciais.

Observa-se que o intuito da Diretiva era definir um padrão de atuação em toda a União Europeia e tais con- siderações, mais uma vez, retiram a possibilidade dessa uniformização, cabendo a cada magistrado a atuação sob sua melhor análise dos procedimentos relacionais aos processos judiciais. Ademais, no presente caso, a Diretiva deveria ter restringido a liberdade de iniciativa das autoridades judiciais aos aspectos de interesse público e direitos fundamentais, não deixando uma cláusula aberta da maneira que consta no art. $9^{\circ}$, pontos 1 e 2 . Trata-se de direitos de comércio, os quais lidam com aspetos de direito privado, não sendo possível a empresa ficar à mercê da iniciativa da autoridade judicial em todos os aspectos, mesmos aqueles restritos a atividades empresarial.

Outra incoerência jurídica foi a definição de que caberá aos Estados-Membros prever os pedidos de indenização e que estes poderiam ser feitos em processos judiciais apartados (2.3) (ponto 5 do art. $11^{\circ}$ da Diretiva). Observa-se que, ao abrir brecha para a definição de cada Estado sobre a aplicação interna desse ponto, retira, mais uma vez, a uniformização defendida pela Diretiva, pois cada Estado poderá definir, internamente, essa questão, atrasando muitas vezes os processos e restituição das indenizações.

Portanto, verifica-se que o objetivo da Diretiva de uniformizar a atuação não será alcançado se referida norma permanecer da maneira definida nessa proposta. Assim, a definição de normas complementares é necessária para viabilizar e operacionalizar essa uniformização. Afinal de contas, somente com a padronização das normas com cláusulas abertas será possível solucionar os problemas jurídicos existentes, garantindo, assim, o alcance do objetivo geral da Diretiva Europeia de Proteção dos Segredos de Negócios contra a aquisição, utilização e divulgação ilegais, qual seja, a padronização para evitar a apropriação indevida de segredos de negócios.

\section{Crônica 2: A crise migratória na Europa e a DECLARAÇÃo UE - TURQUIA SOBRE REFUGIADOS}

\section{INTRODUÇÃo}

Enquanto grande parte dos países do mundo árabe encontra-se imersa em conflitos internos ${ }^{24}$ (assim como

24 E.g: Na Síria, a guerra civil teve início em 2011 e os conflitos entre o Exército Nacional e diversos grupos rebeldes ainda persistem, deixando o país em situação catastrófica. Em junho de 2015, 
vários países do continente africano ${ }^{25}$ ), que envolvem massacres, sequestros, destruição e limpeza étnica, milhões de seus nacionais cruzam fronteiras em fuga, arriscando suas vidas em busca de condições de sobrevivência em outros países, principalmente da Europa.

É provável que uma imagem permaneça ainda por muito tempo na memória de toda a sociedade internacional, a de um menino sírio de 3 anos, afogado, deitado de bruços, na costa da Turquia, a qual, sem dúvidas, despertou uma comoção a nível global, mais profunda do que a alcançada pelas notícias sobre refugiados mortos ou desaparecidos no mediterrâneo que são constantemente veiculadas pela mídia internacional. A criança que aparece em tal imagem, que se transformou em símbolo da crise dos refugiados ${ }^{26}$, pertencia a uma família curda

a Comissão de Investigação Independente para a Síria denunciou ataques indiscriminados contra a população civil, tanto por forças do governo quanto dos grupos rebeldes. ORGANIZAÇÕES DAS NAÇÕES UNIDAS. Centro de Notícias. Síria: comisión investigadora denuncia ataques contra civiles por fuerzas del gobierno y la oposición. 2015. Disponível em: < http://www.un.org/spanish/ News/story.asp?NewsID=32676\#.V1M6upErLIU>. Acesso em: 4 jun. 2016. No Afeganistão, os combates entre grupos rebeldes e o Exército têm se intensificado desde que as forças da OTAN deixaram o país (em 2013, as forças francesas e, no fim de 2014, as forças britânicas e norte-americanas), provocando um aumento no número de vítimas civis no decorrer do último semestre de 2015. Assim como no Afeganistão, a saída das forças norte-americanas não colaborou para melhorar a situação do Iraque. Este país está entregue a uma sangrenta guerra civil entre sunitas e xiitas que já dura mais de dois anos, e a população enfrenta desafios humanitários, como deslocamentos forçados, destruição de casas e dificuldade de acesso à assistência humanitária. ORGANIZAÇÕES DAS NAÇÕES UNIDAS. Centro de Notícias. Oficial da ONU alerta para a necessidade de financiamento a resposta bumanitária no Iraque. 2016. Disponível em: $<$ https://nacoesunidas.org/oficial-da-onu-alerta-para-necessidadede-financiamento-a-resposta-humanitaria-no-iraque/>. Acesso em: 4 jun. 2016.)

25 Argélia, Eritreia, Guiné, Líbia, Nigéria, República Democrática do Congo, Senegal e Somália são exemplos de países africanos que atualmente estão em conflito, configurando pontos de emigração africana para a Europa.

26 Diversos jornais e sites de notícias de todo o mundo publicaram matérias sobre a morte do menino sírio, Aylan Kurdi. Vide: HURTADO, Luís Miguel. Cinco sueños infantiles varados en la playa. 2015. Disponível em: < http://www.elmundo.es/internacional/2015/09 /02/55e6e14022601d69368b458e.html>. Acesso em: 4 jun. 2016; HOMANS, Charles. The boy on the beach. 2015. Disponível em: < http://www.nytimes.com/2015/09/03/magazine/the-boy-on-thebeach.html?_r=0>. Acesso em: 4 jun. 2016; COLON, Leandro. Foto de menino refugiado morto na praia atrai atenção para crise. 2015. Disponível em: <http://www1.folha.uol.com.br/mundo/2015/09/1677028foto-de-menino-refugiado-morto-na-praia-atrai-atencao-para-crise. shtml>. Acesso em: 5 jun. 2016; LE MONDE. Mes enfants m'ont glissé des mains, raconte le père du garçon noyé. 2016. Disponível em: <http:// www.lemonde.fr/europe/article/2015/09/03/la-photographe-del-enfant-syrien-noye-temoigne_4745032_3214.html?xtmc=aylan_ que fugia da Síria ${ }^{27}$ destruída pela guerra utilizando a rota Bodrum-Kos ${ }^{28}$, em busca de um destino seguro na Europa, assim como fazem milhares de outras.

De acordo com os relatórios semanais produzidos pelo Alto Comissariado das Nações Unidas para Refugiados - ACNUR, durante o ano de 2015, 1.015.078 refugiados e migrantes chegaram a Europa pelo mar, preferencialmente via Grécia, Itália e Espanha. ${ }^{29}$ Durante o ano de 2016, até o início do mês de junho, 203.981 fizeram a viagem em busca de segurança na Europa, quase três quartos destes realizaram a travessia da Turquia para a Grécia antes do fim do mês de março. Em termos de nacionalidade, os principais países de origem dos imigrantes na Europa incluem a Síria (41\%), Afeganistão (21\%), Iraque (13\%), Paquistão (3\%) e Irã (2\%), dentre outros. Com relação especificamente aos imigrantes que chegam à Grécia, estes são majoritariamente de países da Ásia Ocidental, tais como Síria (49\%), Afeganistão (26\%), Iraque (15\%), Paquistão (4\%), Irã $(3 \%)$, dentre outros. A Itália, por outro lado, recebeu mais imigrantes provenientes de países africanos, como Nigéria (15\%), Gâmbia (10\%), Somália (9\%), Eritreia $(8 \%)$, Guiné (8\%), Senegal (7\%), Mali (7\%) e Sudão $(5 \%)$, a partir do final do mês de abril. ${ }^{30}$

A atual crise migratória que atinge a Europa não emergiu do dia para a noite, sendo uma problemática já iminente, fruto do prolongamento de sérios conflitos armados em diversos países. Segundo Rahman Siddiqui ${ }^{31}$, uma cruel reviravolta se deu em consequência da emigração

kurdi\&xtcr=69>. Acesso em: 5 jun. 2016.

27 De acordo com relatório do Alto Comissariado das Nações Unidas para Refugiados, a atual crise de refugiados da Síria é a pior em gerações (é a maior depois de 1992), cujo êxodo alcança mais de 4 milhões de pessoas. ORGANIZAÇÕES DAS NAÇÕES UNIDAS. Alto Comissariado das Nações Unidas para Refugiados. More than four million Syrians have now fled war and persecution. 2015. Disponível em: < http://www.unhcr.org/559d648a9.html>. Acesso em: 4 jun. 2016.

28 A rota Bodrum (Turquia) - Kos (Grécia) é a mais curta - mas não menos perigosa - utilizada pelos emigrantes da Ásia Ocidental para atingir a Europa a partir das ilhas gregas.

29 ORGANIZAÇÕES DAS NAÇÕES UNIDAS. Alto Comissariado das Nações Unidas para Refugiados. Refugees/Migrants emergency response: Mediterranean. 2016. Disponível em: $<$ http://data. unhcr.org/mediterranean/regional.php>. Acesso em: 5 jun. 2016.

30 ORGANIZAÇÕES DAS NAÇÕES UNIDAS. Alto Comissariado das Nações Unidas para Refugiados. Weekly report. 2016. Disponível em:< file:///C:/Users/Sarah\%20Dayanna/ Downloads/20160603WeeklyUpdate-Europe'srefugeeemergency. pdf $>$. Acesso em 5 jun. 2016.

31 SIDDIQUI, Fazzur Rahman. The current refugee crisis and the arab states. 2015. p. 1-34. 
de milhões de pessoas da Síria e do Iraque e da urgência destes refugiados e migrantes internacionais diante das fronteiras de diferentes países europeus. O trágico êxodo de indivíduos provenientes de zonas de conflito desafiou toda a lógica das leis de imigração internacional vigentes, colocando em xeque os conceitos jurídicos fundamentais de Estado-nação e soberania, dando início a um debate mais aprofundado acerca da posição política dos Estados em relação a seus assuntos internos (questões como a segurança do país e os interesses de seus nacionais) em oposição ao exercício da solidariedade e da compaixão humana na órbita internacional.

Há décadas, a temática das migrações foi inserida nas agendas nacional e internacional dos países do globo. Paula de Araújo Teixeira ${ }^{32}$ afirma que a concessão de refúgio a pessoas vítimas de perseguições sempre foi vista como uma forma de exercício da solidariedade, porém, diante da atual conjuntura jurídico-política internacional, surgem questionamentos acerca de um retrocesso do instituto do refúgio, sob argumentos de cunho social, econômico e político, especialmente o da priorização da segurança nacional.

\section{O APARATO JURÍDICO INTERNACIONAL DE PROTEÇÃO AOS REFUGIADOS FACE A ATUAL TENDÊNCIA DE FECHAMENTO DE FRONTEIRAS}

Não é a primeira vez que o mundo presencia a magnitude dos efeitos de uma crise migratória. A Ásia, África, América Latina e Europa têm experimentado essa problemática há décadas. No início do século XX, a guerra dos Balcãs obrigou milhares de refugiados da Bósnia e Herzegovina a se distribuírem por diferentes países europeus. Com o fim da Segunda Guerra Mundial, milhões de pessoas vagavam entre os países devastados. Durante a guerra de Bangladesh, em 1971, a Índia também vivenciou uma crise de refugiados. $\mathrm{Na}$ década de 1980, houve a intensificação da crise migratória na América Central: o número de refugiados guatemaltecos no México aumentou, consideravelmente, e países como Honduras e Costa Rica aumentaram a recepção de refugiados vindos, principalmente, de El Salvador, Guatemala e Nicarágua (desde último país saíram cerca

32 TEIXEIRA, Paula de Araújo Pinto. Direitos humanos dos refugiados. Prismas: Direito, Políticas Públicas e Mundialização, Brasília, v. 6, n. 1, p. 15-34, jan./jun. 2009. p. 15. de 15.000 índios mulatos e sumos durante os primeiros meses de 1986). ${ }^{33}$ Essas graves perturbações internacionais deram lugar ao surgimento de um conjunto de normas de proteção aos refugiados, acabando por dar ao refúgio um caráter mais amplo que o asilo.

Diante de problemas internacionais de caráter econômico, social, cultural ou humanitário, a ONU busca soluções mediante o instrumento de cooperação internacional. A proteção dos refugiados foi estabelecida como missão primordial do Alto Comissariado das Nações Unidas para Refugiados, o qual foi constituído para assistir, entre outros indivíduos, aqueles que esperavam para retornar aos seus países após a Segunda Guerra. Foi justamente no seio das ações do ACNUR que o texto da Convenção das Nações Unidas Relativa ao Estatuto $^{34}$ dos Refugiados - CRER começou a ser elaborada.

A CRER, também conhecida como Convenção sobre Refugiados, foi adotada em 1951, entrando em vigor em 22 de abril de 1954, apresentando-se como a Carta Magna do Direito Internacional dos Refugiados. Ela está embasada no artigo 14 da Declaração Universal de Direitos Humanos de 1948, o qual estabelece que "toda pessoa sujeita a perseguição tem o direito de procurar e de beneficiar-se de asilo em outros países." 35

O artigo $1^{\circ}$, A, 2 da Convenção dos Refugiados estabelece que o termo refugiado se aplicará a qualquer pessoa:

Que, em consequência dos acontecimentos ocorridos antes de $1^{\circ}$ de janeiro de 1951 e temendo ser perseguida por motivos de raça, religião, nacionalidade, grupo social ou opiniões políticas, se encontra fora do país de sua nacionalidade e que não pode ou, em virtude desse temor, não quer valer-se da proteção desse país, ou que, se não tem nacionalidade e se encontra fora do país no qual tinha sua residência habitual em consequência de tais acontecimentos, não pode ou, devido ao referido temor, não quer voltar a ele. ${ }^{36}$

33 TRINDADE, Antônio Augusto Cançado; PEYTRIGNET, Gérard; RUIZ DE SANTIAGO, Jaime. As três vertentes da proteção internacional dos direitos da pessoa bumana: direitos humanos, direito humanitário e direito dos refugiados. Brasília: ACNUR, 1996. p. 279.

$34 \mathrm{Na}$ tradução de tal nomenclatura da língua inglesa, qual seja Convention on the Status of Refugees, para o português, altera-se o vocábulo status (atribuição de uma qualificação jurídica) por estatuto. No entanto, cabe ressaltar, que o refúgio é um instituto jurídico, não se confundindo, em momento algum, com um estatuto.

35 ORGANIZAÇÕES DAS NAÇÕES UNIDAS. Assembleia Geral das Nações Unidas. Declaração Universal dos Direitos Humanos. 1948.

36 ORGANIZAÇÕES DAS NAÇÕES UNIDAS. Alto Comis- 
De acordo com a Convenção, o estatuto jurídico de refugiado deve ser aplicado sem qualquer tipo de discriminação e não deve haver nenhuma diferenciação no tratamento dos indivíduos em função de pertença cultural ou étnica. No entanto, a CRER apresentava, inicialmente, duas limitações: uma temporal, visto que seu texto previa que a aplicação de seus dispositivos dar-se-ia apenas às pessoas cujos acontecimentos catalisadores da necessidade de proteção houvessem ocorrido antes de $1^{\circ}$ de janeiro de 1951; e outra geográfica, fazendo menção aos locais de ocorrência dos acontecimentos que ocasionaram a necessidade do refúgio (somente na Europa, ou na Europa e em outros locais). Para contornar tais deficiências, em 31 de janeiro de 1967, foi aprovado, em Nova York, o Protocolo Relativo ao Estatuto de Refugiados - PRER. Esse documento, que somado à CRER constitui o núcleo normativo central da proteção universal dos refugiados, eliminou a limitação temporal. A reserva geográfica, contudo, não foi modificada pelo PRER, estando, portanto, ainda vigente. Nesse contexto, o ACNUR em muito tem trabalhado para convencer os Estados de, além de aderirem à CRER, que o façam sem estabelecer a reserva geográfica. ${ }^{37}$

A CRER proíbe a expulsão e o regresso forçado das pessoas que beneficiam do estatuto de refugiado. Nos termos do artigo $33^{\circ}$, "nenhum dos Estados Contratantes expulsará ou repelirá um refugiado, seja de que maneira for, para as fronteiras dos territórios onde a sua vida ou a sua liberdade sejam ameaçadas em virtude da sua raça, religião, nacionalidade, filiação em certo grupo social ou opiniões políticas". Outras disposições referem-se a direitos, como o acesso aos tribunais, a educação, segurança social, habitação e liberdade de circulação. A Convenção, também, estabelece que, em regra, os refugiados não podem ser penalizados por imigração ilegal ou por violação à lei de nações anfitriãs.

Não obstante a existência de normas jurídicas internacionais que versam sobre a proteção dos refugiados, as crises migratórias ainda configuram uma problemática recorrente no cenário internacional. Como agravante, os atentados terroristas efetuados, desde 2001, em Nova York, Madri, Londres e, mais recentemente, em

sariado das Nações Unidas para Refugiados. Convenção das Nações Unidas relativa ao estatuto dos refugiados. 1951.

37 TRINDADE, Antônio Augusto Cançado; PEYTRIGNET, Gérard; RUIZ DE SANTIAGO, Jaime. As três vertentes da proteção internacional dos direitos da pessoa bumana: direitos humanos, direito humanitário e direito dos refugiados. Brasília: ACNUR, 1996. p. 269.
Paris e Bruxelas influenciaram na mudança de posicionamento de alguns países acerca da entrada e permanência de estrangeiros em seus territórios, surgindo daí uma tendência ao fechamento de fronteiras como meio de garantir a segurança nacional e combater o terrorismo, em nome da ordem pública e da soberania estatal. Foi nesse contexto que se deu a celebração do acordo entre União Europeia e Turquia em resposta à atual crise de refugiados, na tentativa de frear o fluxo migratório.

\section{A VIGÊnCIA DA DECLARAÇÃo UE-TURQUIA E A INSATISFAÇÃO DA ONU COM TAL RESPOSTA À ATUAL CRISE MIGRATÓRIA}

Em 29 de novembro de 2015, após várias semanas de negociação, União Europeia e Turquia deram início a um plano de ação para conter o fluxo de refugiados sírios e outros migrantes irregulares para a Europa. Em uma cúpula em Bruxelas, a UE comprometeu-se a dar 3 bilhões de euros para ajudar os refugiados na Turquia e conceder visto de viagem para os nacionais turcos a partir de outubro de 2016. Em troca, a Turquia ficaria responsável por interromper o fluxo descontrolado de migrantes para a Europa e enfrentar, a longo prazo, as necessidades dos refugiados presentes em seu território (principalmente o acesso à educação e a oportunidades econômicas). ${ }^{38}$

A Declaração UE-Turquia, que entrou em vigor no dia 20 de março de 2016, é fruto do plano de ação implementado desde novembro de 2015, consistindo no fechamento de fronteira aos imigrantes irregulares que chegam à Grécia pelo território turco.

Segundo Eduard Soler i Lecha ${ }^{39}$, a Turquia é um elemento essencial da atual crise de refugiados, sendo estratégica a celebração de um acordo entre a mesma e a UE, por três razões. Primeiramente, a Turquia, sozinha, recebeu mais de 2 milhões de refugiados sírios até novembro de 2015. Em segundo lugar, existem estimativas de crescimento dos números de refugiados no território turco em decorrência dos conflitos persistentes nos

38 KIRIŞCI, Kemal. How the EU and Turkey can work together on refugees. In: BROOKINGS INSTITUTION. Order from chaos: foreign policy in a troubled world. 2015. p. 1-4.

39 SOLER I LECHA, Eduard. Turkey makes itself indispensable. In: MORILLAS, SÁNCHEZ-MONTIJANO, SOLER, (Coord.). Europe and the refugee crisis. Barcelona: CIDOB edicions, 2015. 
países vizinhos. Em terceiro lugar, a Turquia se tornou um centro migratório, a principal plataforma a partir da qual os sírios, afegãos e iraquianos tentam entrar no território europeu.

O objetivo da Declaração UE-Turquia é pôr fim à migração irregular do território turco para o europeu, buscando desmantelar o modelo de negócio dos passadores e fornecer aos migrantes uma alternativa que não implique risco as suas vidas. Conforme comunicado de imprensa do Conselho Europeu ${ }^{40}$, com a finalidade de atingir tal objetivo, UE e Turquia acordaram em relação aos seguintes pontos:

Todos os migrantes irregulares que chegarem às ilhas gregas provenientes da Turquia a partir de 20 de março de 2016 serão devolvidos ao território turco. ${ }^{41}$ Trata-se de uma medida temporária e extraordinária, necessária para pôr fim ao sofrimento das pessoas e restabelecer a ordem pública, sendo tomada em plena conformidade com o direito da UE e as normas internacionais pertinentes.

Os migrantes que chegam às ilhas gregas serão devidamente registrados e todos os pedidos de asilo serão tratados individualmente pelas autoridades gregas em conformidade com a Diretiva "Procedimentos de Asilo" 42 , em cooperação com o ACNUR. Os migrantes que não pedirem asilo ou cujos pedidos tenham sido considerados infundados ou não admissíveis, nos termos da referida diretiva, serão devolvidos à Turquia (excluindo-se, assim, qualquer tipo de expulsão coletiva).

Por cada sírio devolvido à Turquia a partir das ilhas gregas, outro sírio proveniente da Turquia será reinstalado na UE, tendo em conta os critérios de vulnerabilidade das Nações Unidas. ${ }^{43}$

40 CONSELHO EUROPEU. Declaração UE-Turquia de 18 março de 2016. 2016. Disponível em: <http://www.consilium.europa.eu/pt/ press/press-releases/2016/03/18-eu-turkey-statement/>. Acesso em: 6 jun. 2016.

41 Os custos das operações de regresso dos migrantes irregulares serão assumidos pela UE.

42 "Procedimentos de Asilo" consiste na Diretiva 2005/85/CE do Conselho Europeu, de 1 de dezembro de 2005, relativa a normas mínimas aplicáveis ao procedimento de concessão e retirada do estatuto de refugiado dos Estados-Membros. Uma nova Diretiva, a 2013/32/UE do Parlamento Europeu e do Conselho, foi criada em 26 de junho de 2013 e começou a ser aplicada em 21 de julho de 2015, mostrando-se mais rigorosa do que a anterior. Vide: COMISSÃO EUROPEIA. Sistema Europen comum de asilo. Luxemburgo: Serviço das Publicações da União Europeia, 2014. p. 4. Disponível em: <http://ec.europa.eu/dgs/home-affairs/e-library/docs/ceasfact-sheets/ceas_factsheet_pt.pdf $>$. Acesso em: 7 jun. 2016.

43 Será dada prioridade aos migrantes que não tenham anterior-
A Turquia tomará todas as medidas necessárias para evitar a abertura de novas rotas marítimas ou terrestres para a migração ilegal desde seu território até países europeus, e cooperará nesse sentido com os Estados vizinhos, bem como com a UE.

Tão logo deixem de haver travessias irregulares entre Turquia e EU, ou se registre, pelo menos, uma substancial e sustentada redução das mesmas, será ativado um programa voluntário de admissão de migrantes por motivos humanitários. ${ }^{44}$

A UE, em estreita cooperação com a Turquia, acelerará o desembolso dos 3 bilhões de euros em favor dos refugiados na Turquia e assegurará o financiamento de outros projetos destinados às pessoas que se beneficiam de proteção temporária na Turquia.

A UE e os seus Estados-Membros trabalharão com a Turquia em iniciativas conjuntas para melhorar as condições humanitárias no interior da Síria, em especial em certas áreas próximas da fronteira com a Turquia, o que permitirá à população local e aos refugiados viver em zonas mais seguras.

Conclui-se que tal acordo foi celebrado como uma espécie de "toma lá, dá cá"45, proporcionando vantagens mútuas entre as partes negociantes. Paradoxalmente, uma crise de refugiados, que, até então, havia sido um fardo para o governo turco, tornou-se uma oportunidade. Agora, a Turquia pode exigir que a UE assuma parte da responsabilidade por meio da quantia proposta para custeio da recepção de refugiados. Até 2015, a Turquia havia gasto 6 bilhões de euros (essa não é uma soma desprezível em um país cuja economia cresce apenas 3\% ao ano), provenientes de seus próprios recursos, na construção de campos para refugiados e na prestação de serviços sociais básicos para os mesmos. ${ }^{46} \mathrm{~A} \mathrm{UE}$, por sua vez, trabalhará cooperativamente com o país utilizado como principal ponto de partida de refugiados e migrantes da Ásia Ocidental, no sentido de evitar a entrada de grande número de pessoas nos territórios

mente entrado ou tentado entrar de forma irregular na UE.

44 Os Estados-Membros da UE contribuirão de forma voluntária para esse programa.

45 Como sinônimos desta expressão popular brasileira, Kemal Kirişci utiliza os termos "win-win" e "I'll scratch your back, you scratch mine".

46 Os desafios mais prementes enfrentados pela Turquia são o fornecimento de comida e abrigo fora dos campos de refugiados, a garantia de educação para as crianças e oferecimento de oportunidades de trabalho para os adultos. 
de seus Estados-Membros, medida que foi tomada com caráter de urgência.

Vale ressaltar que, embora as partes negociantes defendam suas razões para a implementação da Declaração UE-Turquia, existem divergências em âmbito internacional acerca da fundamentação de tal acordo. Alguns líderes políticos e organizações não governamentais que trabalham em prol dos direitos humanos se mostram desconfortáveis com relação a essa tratativa, uma vez que a mesma levaria a instrumentalização do bem-estar dos refugiados para servir aos interesses da União Europeia e Turquia. Ademais, a ONU não corrobora com o posicionamento das partes de tal acordo frente a crise migratória.

Antes da vigência da declaração, o ACNUR já havia manifestado sua preocupação com relação a uma resposta europeia à crise migratória que envolvesse o envio de indivíduos de um país para outro sem a adoção de garantias de proteção aos refugiados sob a lei internacional, tendo ressaltado, ainda, que os indivíduos que retornassem à Turquia e tivessem necessidades de reassentamento específicas, como reunificação de famílias, deveriam ser considerados para o programa de reassentamento/admissão da EU. ${ }^{47}$ Após a entrada em vigor da declaração, o ACNUR anunciou não fazer parte do acordo entre UE e Turquia, uma vez que a agência mantém a política de se opor a prisões mandatórias, suspendendo, por isso, suas atividades nos "hotspots" 48 das ilhas gregas.

O Alto Comissário das Nações Unidas para Direitos Humanos, Zeid Ra'ad al Hussein, expressou grave preocupação com a linguagem do acordo, o qual apresentaria um risco real de não atender as obrigações do Direito Internacional dos Direitos Humanos, que exigem que os Estados-membros examinem os argumentos contra a deportação para além daqueles encontrados no Direito Internacional dos Refugiados. Segundo o Alto Comissário, "se a UE começa a contornar a lei internacional, poderia haver um efeito similar em outras partes do mundo, profundamente problemático." 49

47 ORGANIZAÇÃO DAS NAÇÕES UNIDAS. ACNUR manifesta preocupação com acordo entre UE e Turquia sobre refugiados. 2016. Disponível em: <https://nacoesunidas.org/acnur-manifesta-preocupacao-com-acordo-entre-ue-e-turquia-sobre-refugiados $/>$. Acesso em: 7 jun. 2016

48 "Hotspots" são os locais onde os refugiados e migrantes são recebidos, assistidos e registrados.

49 ORGANIZAÇÃO DAS NAÇÕES UNIDAS. ACNUR diz não
Crônica 3: A lista negra do ConselHo de DIREITOS HUMANOS: A ATIVIDADE DAS EMPRESAS NOS TERRITÓRIOS OCUPADOS APÓS A RESOLUÇÃO DA ONU

\section{INTRODUÇÃo}

O Conselho de Direitos Humanos é um órgão inter-gorvenamental, que, dentro do âmbito das Nações Unidas, é responsável pela promoção e proteção dos direitos humanos em todo o mundo, e para a resolução de situações de violações dos direitos humanos. Desde 2009, a situação dos direitos humanos nos Territórios Ocupados da Palestina, é regularmente informada ao Conselho pelo Escritório do Alto Comissariado das Nações Unidas para os Direitos Humanos no território palestino ocupado.

Em um dos relatórios emitido pelo Alto Comissariado, em 2013 ${ }^{50}$, observou-se que empresas plenamente consciente da situação opressiva vivida pela população árabe nos territórios ocupados têm cooperado com a manutenção e consolidação dos assentamentos israelenses, em troca dos inúmeros incentivos a elas oferecidos. O crescimento dessas atividades comerciais nas zonas dominadas por israelenses, além de colocar em desvantagem o mercado palestino, limitando-o financeira e economicamente, tem causado a escassez dos recursos naturais palestinos, para o abastecimento dos assentamentos e empresas.

Como no caso do Vale do Jordão, em que $83 \%$ dos recursos hídricos extraídos dessa região destinam-se ao abastecimento dos assentamentos israelenses, tendo a companhia nacional de águas israelenses (Mekorot) e Mehadrin, uma empresa agroindustrial, secado poços e mananciais palestinos, em razão das perfurações feitas. ${ }^{51}$

fazer parte do acordo entre UE e Turquia redesenha atuação na Grécia. 2016. Disponível em: <https://nacoesunidas.org/acnur-diz-nao-fazerparte-de-acordo-entre-ue-e-turquia-redesenha-atuacao-na-grecia/ $>$. Acesso em: 8 jun. 2016.

50 ORGANIZAÇÃO DAS NAÇÕES UNIDAS. Conselho de Direitos Humanos. Resolução A/HRC/22/63. 1963. Disponível em: $<$ http://www.ohchr.org/Documents/HRBodies/HRCouncil/RegularSession/Session22/A-HRC-22-63_en.pdf>.

51 ORGANIZAÇÃO DAS NAÇÕES UNIDAS. Conselho de Direitos Humanos. Resolução A/HRC/22/63. Disponível em: <http://www.ohchr.org/Documents/HRBodies/HRCouncil/ RegularSession/Session22/A-HRC-22-63_en.pdf>. p. 18 -item 82. 
Preocupado com as consequências das atividades econômicas nos Territórios Ocupados ${ }^{52}$, e tendo verificado, com base no mais recente relatório emitido pelo Alto Comissionado das Nações Unidade para os Direitos Hu$\operatorname{manos}^{53}$, que as recomendações anteriores apresentadas pelo Alto Comissariado ${ }^{54}$, não foram acolhidas, o Conselho de Direitos Humanos decidiu adotar em 22 de março de 2016, por meio da resolução A/HRC/31/L.39, uma medida de controle mais firme, requerendo a elaboração de uma base de dados de todas as empresas envolvidas em atividades empresariais nos Territórios Ocupados.

$\mathrm{Na}$ mesma oportunidade, três outros relatórios foram abrangidos pela resolução: 1) efeitos da demolição de casas, despejos, assentamentos em expansão, violência dos colonos e politicas de zoneamento e planejamento discriminatórias em termos econômicos, direitos sociais e culturais dos palestinos; 2) maneira de ocupação e as medidas conexas de restrição a liberdade de circulação e suas consequências nos direitos dos palestinos; 3) necessidade efetiva de se proteger os direitos dos palestinos.

\section{DO RESPEITO AOS PRINCÍPIOS ORIENTADORES DE DIREITOS HUMANOS À LISTA NEGRA DA ONU}

A resolução A/HRC/31/L.39 surge como resposta ao noticiado no último relatório apresentado por Makarim Wibisono, Relator Especial da ONU sobre a situação dos direitos humanos nos territórios palestinos ocupados, que enfatiza a desesperada necessidade em se conferir uma proteção mais efetiva aos palestinos nos territórios ocupados. Principalmente, diante da recusa de Israel em respeitar as recomendações da ONU, mantendo condutas de constantes violações às leis humanitárias, como a expansão dos assentamentos em territórios ocupados, que contam com o envolvimento de empresas na exploração de recursos naturais.

O auxilio prestado por empresas ao Estado de Israel, em relação à exploração de recursos naturais dos terri-

52 ORGANIZAÇÃO DAS NAÇÕES UNIDAS. Conselho de Direitos Humanos. Resolução A/HRC/28/26. Disponível em: <https://documents-dds-ny.un.org/doc/UNDOC/GEN/ G15/030/65/PDF/G1503065.pdf?OpenElement>.

53 ORGANIZAÇÃO DAS NAÇÕES UNIDAS. Conselho de Direitos Humanos. Resolução A/HRC/31/42. Disponível em: <https://unispal.un.org/DPA/DPR/unispal.nsf/0/0CCE8667AB23D 63B85257F62005027A3>.

54 ORGANIZAÇÃO DAS NAÇÕES UNIDAS. Conselho de Direitos Humanos. Resolução A/HRC/31/42. Disponível em: <https://unispal.un.org/DPA/DPR/unispal.nsf/0/0CCE8667AB23D 63B85257F62005027A3>. tórios palestinos e expansão de assentamentos, mostra-se como o principal responsável pelas fragmentações operadas na Cisjordânia e aprofundamento das restrições de movimento/acesso do povo palestino ${ }^{55}$. Ciente dessa situação, o Conselho de Direitos Humanos inicia a resolução A/HRC/31/L.39, fazendo uma retomada dos princípios orientadores das Empresas e Direitos Humanos, e segue recordando a responsabilidade das empresas e Estados, em se absterem de contribuir para as violações de direitos humanos. ${ }^{56}$

Essa reiteração do dever das empresas em respeitar as normas de direito internacional humanitário, ao longo de toda a resolução A/HRC/31/L.39, além de demonstrar a extrema preocupação do Conselho com a falta de compromisso de muitos Estados e empresas em atuar em conformidade com as leis internacionais, visa, também, recordar os riscos de caráter jurídico e financeiro que as empresas podem incorrer caso suas atividades contribuam de alguma forma com o conflito.

Após toda essa recordação e reiteração do dever das empresas para com a proteção dos direitos humanos, a resolução, culmina com a solicitação ao Alto Comissariado das Nações Unidades de Direitos Humanos, o qual em estreita consulta com o Grupo de Trabalho sobre a questão de direitos humanos e empresas transnacionais e outras empresas, deverá elaborar uma "lista negra", a ser atualizada anualmente, com os dados de todas as companhias que participem ou contribuam com as atividades nos assentamentos israelenses ${ }^{57}$.

\section{AusênCia de Respostas para as INQUIETAÇÕES GERADAS}

Embora aprovada por ampla maioria de 32 votos

55 C.f. Disponível em: <http://www.ohchr.org/EN/NewsEvents $/$ Pages $/$ DisplayNews.aspx?NewsID=18496\&LangID=E $>$.

56 ORGANIZAÇÃO DAS NAÇÕES UNIDAS. Conselho de Direitos Humanos. Resolução A/HRC/31/L.39. p. 4. Disponível em: $<$ https://unispal.un.org/DPA/DPR/unispal.nsf/0/827CFB70406 8F7B985257F850071154A>.

57 Atividades que contribuem para a anexação e exploração de terras palestinas e dos recursos naturais, alterações demográficas através da transferência de população, negação do direito à autodeterminação do povo palestino, todas as que violem o direito internacional. ORGANIZAÇÃO DAS NAÇÕES UNIDAS. Conselho de Direitos Humanos. Resolução A/HRC/22/63. parágrafo 96. Disponível em: <http://www.ohchr.org/Documents/HRBodies/HRCouncil/RegularSession/Session22/A-HRC-22-63_en.pdf>. 
a favor, nenhum contra e 15 abstenções, entre elas do Estado de Israel, a posição adotada pelo Conselho de Direitos Humanos, gerou polêmica entre países como Alemanha, Reino Unido e Holanda, os quais manifestaram preocupação que a elaboração de uma base de dados, estimule ações de boicote e sanções contra as empresas listadas.

Essa inquietação é compreensível, uma vez que as violações operadas por Israel contra os povos dos Territórios Ocupados passaram a ter maior representatividade e, por consequência, notoriedade no âmbito internacional, após o reconhecimento da Palestina como Estado Observador pela Assembleia Geral da ONU, em 2012. E, tal como aconteceu na África do Sul, as pressões internacionais por sanções jurídicas às empresas e boicote aos produtos sul africanos, se intensificaram após a divulgação mundial da bárbara política segregacionista aplicada no país, acelerando o fim do regime.

Contudo, verifica-se que a resolução ecoa uma comunicação interpretativa, lançada pela União Europeia em 2015, que proíbe a importação de produtos rotulados como "Made in Israel", mas produzidos em território, ou com recursos palestinos ${ }^{58}$, alegando para tanto o seu dever de não reconhecer a soberania de Israel sobre os territórios palestinos ocupados e as leis de defesa do consumidor da UE. Uma vitória para o movimento BDS, que busca o boicote, não investimento e sanções contra Israel, para acabar com sua ocupação militar.

Entre as principais exportadoras israelenses alvos do boicote estão os vinhos produzidos nas Colinas de Golã e Cisjordânia, e rotulados como israelenses; os produtos da empresa Sodastream, cuja unidade central de produção está localizada na zona industrial de Mishor Edomin, um assentamento ilegal na Cisjordânia; e Eden Spring, empresa israelense que extrai água de Salukia spring, localizada no território ocupado de Golã ${ }^{59}$.

Finalmente, nota-se que, após anos de omissão das Nações Unidas em regulamentar e controlar, a situação de violação aos direitos humanos praticados por empresas nos territórios ocupados, a inquietação em resguardar os direitos humanos, passou a figurar como tema central da agenda de muitos países investidores.

58 C.f. Disponível em: <https://eeas.europa.eu/delegations/ israel/documents/news/20151111_interpretative_notice_indication_of_origin_of_goods_en.pdf $>$.

59 C.f. Disponível em: < https://bdsmovement.net/activecamps/ consumer-boycott>.
Seja para se prevenirem de eventuais sanções, ou por uma mudança de consciência. De todo modo, o Conselho de Direitos Humanos da ONU viu-se compelido a adotar uma resolução que viesse ao encontro das novas demandas socioempresariais.

Apesar de seu atraso em ser elaborada, a resolução, ainda assim, representa uma importante vitória para o reconhecimento dos direitos dos povos que residem nos territórios ocupados. Contudo, as inquietações geradas deverão aguardar uma possível resposta, com o novo relatório do Secretário-Geral que será apresentado no $34^{\circ}$ período de sessões ${ }^{60}$, ou seja, em março de 2017 , e só então verificaremos se os direitos humanos vencerão a batalha contra os interesses econômicos.
60 ORGANIZAÇÕES DAS NAÇÕES UNIDAS. Conselho de Direitos Humanos. Resolução A/HRC/31/L.39. p. 9 item 18. Disponível em: <https://unispal.un.org/DPA/DPR/unispal.nsf/0/82 7CFB704068F7B985257F850071154A>. 
Para publicar na Revista de Direito Internacional, acesse o endereço eletrônico www.rdi.uniceub.br ou www.brazilianjournal.org.

Observe as normas de publicação, para facilitar e agilizar o trabalho de edição. 